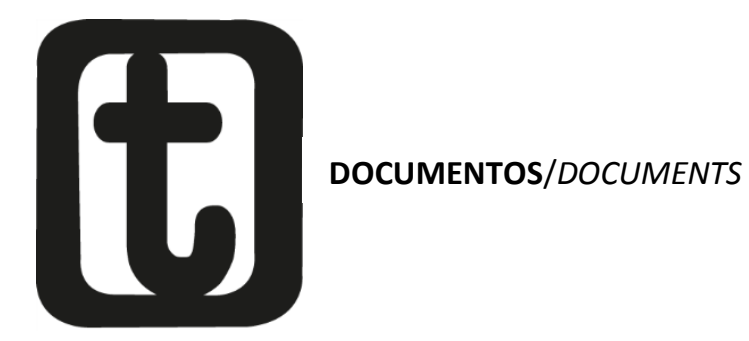

\title{
CFESS MANIFESTA
}

CFESS states

É preciso voltar brutalmente a atenção para o presente tal como é, se se quer transformá-lo. Gramsci

Às vésperas do dia do/a Assistente Social, o Conjunto CFESS-CRESS, a ABEPSS e a ENESSO, com apoio do Sindicato Nacional dos Docentes das Instituições de Ensino Superior (ANDES - SN), lançaram a campanha nacional Educação não é fast-food: diga não para a graduação a distância em Serviço Social. Desde então, as entidades do Serviço Social brasileiro vêm recebendo inúmeras mensagens de apoio à luta em defesa da formação profissional com qualidade, mas, também, recebemos críticas de pessoas envolvidas com os cursos de graduação a distância em Serviço Social. Neste sentido, nossa campanha já revela seus primeiros frutos, pois estamos instaurando um debate público acerca da formação profissional e, consequentemente, dos rumos do ensino superior no país. O conteúdo teórico, empírico e político dessa campanha expressa o compromisso das entidades com a educação superior pública, gratuita, laica e de qualidade, voltada para atender às necessidades da população brasileira e enfrentar a precarização e mercantilização das políticas sociais, bem como as desigualdades no país. Essa bandeira de luta histórica é também de um conjunto de movimentos sociais que, ao incorporá-la, evidencia

Temporalis, Brasilia (DF), ano 11, n.21, p.281-288, jan./jun. 2011. 


\section{temporalis}

que a graduação com qualidade e gratuidade não se coaduna com os cursos de graduação a distância.

Tais cursos, direcionados para os interesses de mercado, não asseguram os compromissos e princípios da educação superior como direito de todos/as e como dever do Estado. Não garantem a articulação entre ensino, pesquisa e extensão, indispensável à formação na perspectiva de totalidade de um/a profissional. Esses cursos de graduação a distância inviabilizam o processo formativo básico na perspectiva de totalidade e criticidade na apreensão da realidade. Desvirtuam o acesso à bibliografia adequada às exigências curriculares e à realização do estágio supervisionado, de modo presencial e com acompanhamento dos/as supervisores/as acadêmico/a e de campo. Além disso, negam a realização da pesquisa e da investigação como princípio formativo que deve perpassar todo o currículo da graduação.

Desde 2000, quando da realização de um seminário com a participação das três entidades representativas da categoria de Assistentes Sociais para análise da Lei de Diretrizes e Bases da Educação (LDB, 1996) e suas consequências para o ensino superior, vimos mantendo uma posição crítica à presença das forças de mercado na educação, incorporada largamente pela legislação brasileira, cuja maior expressão são as normas de apoio e incentivo ao Ensino a Distância (EaD).

Assim, o debate sobre esta modalidade de ensino requer considerar diversos elementos, como: a configuração das políticas públicas e dos direitos fundamentais em nosso país; os interesses das empresas/instituições, sejam elas internacionais, transnacionais, nacionais, privadas ou públicas; as necessidades e demandas dos/as estudantes nas mais diversas regiões do país, das associações de docentes e discentes. 


\section{tempordils}

Considerando a necessidade de aprofundamento sobre todos esses elementos, bem como levantamento de dados sobre a realidade do ensino de graduação a distância, para o seu consequente enfrentamento, em setembro de 2008, a partir de seu $37^{\circ}$ Encontro Nacional, o Conjunto CFESS-CRESS constituiu o Grupo de Trabalho e Formação Profissional, formado pelo CFESS, por um/a representante dos CRESS de cada região do país e por um/a representante das direções nacionais da ABEPSS e da ENESSO, com o objetivo de construir e monitorar a implementação de um Plano de Lutas em Defesa do Trabalho e da Formação e Contra a Precarização do Ensino Superior, em face das mudanças suscitadas pela promulgação da LDB, em 1996. Com a finalização do Plano em abril de 2009, desencadeamos estratégias de colher o máximo de informações sobre a precarização do ensino superior, especialmente sobre a penetração do EaD, no âmbito da graduação em Serviço Social.

O documento intitulado Sobre a incompatibilidade entre graduação a distância e Serviço Social tornou público os resultados do trabalho produzido pelo esforço conjunto dos CRESS e das Diretorias Regionais da ABEPSS, que reuniram dados e informações que retratam a precária situação dos cursos de graduação a distância ofertados nas cinco regiões do Brasil.

Como estratégias para a coleta desses dados, foram realizados diversos procedimentos, desde a pesquisa documental - incluindo documentos disponibilizados pelas próprias Instituições de Ensino, as legislações sobre o EaD, sites, materiais didáticos utilizados pelos cursos - passando pela realização de reuniões com estudantes, tutores/as, assistentes sociais supervisores/as de estágio e coordenadores/as dos pólos, até a realização de visitas em telessalas e núcleos de formação do Ensino a Distância. Todos esses procedimentos oportunizaram um melhor conhecimento da

Temporalis, Brasilia (DF), ano 11, n.21, p.281-288, jan./jun. 2011. 


\section{temporalis}

organização e da dinâmica de funcionamento dos cursos de graduação a distância em Serviço Social.

A análise dos dados reunidos demonstrou o descompromisso das Instituições de Ensino com a formação profissional substantivamente de qualidade e a falta de controle e acompanhamento sistemático da expansão e prestação de serviços dessas instituições por parte do Ministério da Educação (MEC).

O processo de credenciamento junto ao MEC tem ocorrido de maneira superficial, não estabelecendo condicionalidades para a avaliação estatal in loco com vista à confirmação das informações prestadas pelas instituições proponentes, como ocorre nos casos dos cursos de graduação presenciais. Os dados identificados sobre o processo global de formação (bibliografias utilizadas, dinâmica pedagógica, avaliações, estágio curricular, perfil dos/as tutores/as e outros componentes relacionados ao projeto pedagógico) confrontam radicalmente com nossos compromissos e princípios. Colidem, também, com os conteúdos, habilidades e competências estabelecidas nas Diretrizes Curriculares para os cursos de Serviço Social e com os instrumentos normativos afetos ao estágio (Lei 11.788/2008, Resolução CFESS 533/2008 e Política Nacional de Estágio/ABEPSS) e, ainda, com as atribuições e competências dos/as assistentes sociais previstas na Lei 8.662/1993.

Todos esses elementos consubstanciam nossa veemente defesa de incompatibilidade entre graduação a distância e Serviço Social. Ou seja, diante das fragilidades e irregularidades constatadas, também não identificamos, no acúmulo das informações e das análises, a possibilidade de qualificar tais cursos. Ainda que tenhamos clareza de que os processos de precarização da educação também atingem os cursos presenciais, há nichos de resistências. É possível 


\section{tempordils}

detectar esforços de professores/as e de alunos/as nesses espaços para assegurarem a materialização da formação profissional com qualidade. Na graduação a distância, centrada no ensino virtual ou mediado por mídias, essa condição é inviabilizada, diante da atomização das telessalas e pólos, das vivências individuais do processo de ensino-aprendizagem, que não possibilitam as práticas organizativas e coletivas dos/as estudantes e dos/as trabalhadores/as envolvidos/as.

Essa posição não significa, por parte do Conjunto CFESS-CRESS, uma negação ou a desqualificação do processo de avanços tecnológicos. Técnicas e invenções pedagógicas que combinem tecnologia e interatividade podem e devem ser suporte ao processo de ensino-aprendizagem presencial, mas não substituem, de forma alguma, o diálogo, o encontro, a pesquisa, a extensão, a orientação, a supervisão direta e a organização política dos sujeitos participantes do processo educacional.

Nossos posicionamentos não são fundados no desconhecimento e no preconceito, nem são dirigidos aos/às estudantes e trabalhadores/as do EaD. Na verdade, a campanha marca nossa discordância com a política brasileira de ensino superior, profundamente mercantilizada e discriminatória. Uma política que reforça as desigualdades sociais e regionais do país; que assegura aos ricos o ensino de qualidade e aos que não possuem condições para acessar as poucas instituições de graduação públicas presenciais ou de custear a sua própria formação de qualidade são ofertados os cursos de EaD - expressão máxima da precarização e da mercantilização da educação. Essa lógica expansionista da educação reflete a perfeita combinação entre os interesses do mercado interno e os interesses políticos governamentais de elevação dos indicadores quantitativos relativos ao ensino superior, para atrair novos investimentos estrangeiros para o país.

Temporalis, Brasilia (DF), ano 11, n.21, p.281-288, jan./jun. 2011. 


\section{temporalis}

Essa expansão não garante acesso democrático ao ensino, tampouco assegura sua qualidade.

Portanto, nossa campanha não é excludente, nem preconceituosa, nem discriminatória. Ao contrário, nossa defesa é da democratização do acesso, pela via da igualdade de condições e não pela falácia da igualdade de oportunidades; pela via do reconhecimento e materialização da educação como direito e não como mercadoria. O ônus da política educacional mercantilizada que vem sendo feita por sucessivos governos não deve recair sobre os/as estudantes e trabalhadores/as envolvidos/as com EaD, e muito menos sobre as entidades de Serviço Social.

Nossa tarefa é exigir do Estado a igualdade de acesso ao ensino superior presencial para todos/as e a garantia da qualidade da oferta. Trata-se de denunciar quem se beneficia com a educação a distância: de um lado, os tubarões do ensino - que ficam cada vez mais ricos e que têm um único objetivo: vender uma mercadoria; de outro, o governo - que se desobriga da execução da política pública de educação e acena com a mão do mercado para o EaD como única saída. Desse modo, o ensino de graduação a distância assume a condição de um novo fetiche social, pois, em nível da aparência do fenômeno, apresenta-se como democratização do acesso, o que esconde sua essência mercantil.

Reafirmamos, portanto, que reconhecemos a legitimidade da demanda dos/as estudantes de terem acesso ao ensino superior gratuito e de qualidade. Além de um direito, essa é uma condição especialmente importante num país em que grande parte da População Economicamente Ativa (PEA) não tem ocupação ou emprego com direitos trabalhistas garantidos e a formação superior ainda constitui um elemento diferencial para essas conquistas. 


\section{temporolis}

No Brasil, o ensino superior é privilégio de poucos. Mais de $80 \%$ dos cursos são oferecidos por instituições privadas. 0 discurso falacioso da democratização pode ser facilmente identificado se observarmos a forma como o governo tem atendido às diferenças regionais de acesso ao ensino superior - na região Norte, por exemplo. Nota-se que, em detrimento do aumento de vagas em Instituições de Ensino públicas e presenciais ou da criação de cursos de Serviço Social nas Universidades Públicas que ainda não o têm, ocorre a massificação via EaD ou a utilização do fundo público para financiar bolsas de estudos nas Instituições privadas, através da ampliação do PROUNI. Esta é a viva expressão de um projeto de nação que não atende aos interesses das maiorias.

O direito ao ensino superior gratuito e de qualidade urge ser materializado em condições de oferecer aos/às estudantes formação crítica que os/as prepare para o exercício profissional e também amplie suas condições de atuar em um mundo cada vez mais complexo, na perspectiva de torná-lo substantivamente igualitário e humano. Exige ainda ser materializado de forma a oferecer aos/às docentes condições de trabalho dignas, com estabilidade e direitos trabalhistas garantidos, com regulamentação do cargo e da jornada, além de salário compatível com a responsabilidade das atribuições que desenvolve. Tutor/a não é professor/a. Tutor/a não é supervisor/a acadêmico/a de estágio. Aula não é tutoria. O processo de ensino-aprendizagem em Serviço Social não se encerra nos conhecimentos específicos da profissão; necessita de um conjunto de outras ciências, sem as quais não conseguimos decifrar a realidade na sua totalidade e complexidade.

Todo este contexto aponta os níveis de desigualdades que atingem o Brasil e nos fazem reforçar uma campanha conduzida pelo Conjunto CFESS-CRESS anos atrás: O Brasil precisa de Assistentes Sociais. O que se problematiza neste momento é a produção de profissionais em massa 


\section{tempordils}

e com conteúdos banalizados. É a qualidade do ensino que está sendo oferecido que não assegura o perfil profissional previsto nas Diretrizes Curriculares. É a educação bancária e mercantilizada que não garante o Serviço Social comprometido com as mudanças que o Brasil precisa para se tornar verdadeiramente democrático e justo. O país precisa de assistentes sociais capacitados/as em uma perspectiva de totalidade e crítica para defender direitos, formular e executar políticas sociais capazes de reduzir as desigualdades e combater a violência em todas as suas expressões. Esta, longe de ser uma posição meramente ideológica, refere-se à firme defesa da densidade teórico-prática e ético-política que deve orientar a formação do/a profissional de qualidade que o país requer.

Por isso, convidamos os/as estudantes e trabalhadores/as para se somarem à luta histórica em defesa do ensino público, universal, gratuito, presencial e laico. Exigimos do MEC a ampliação de vagas com qualidade para atender à demanda por ensino superior no Brasil. O enfrentamento da precarização da formação profissional nos remete à indissociabilidade entre formação e exercício profissional e, portanto, precisa ser do interesse de todos/as os/as estudantes, assistentes sociais e da própria sociedade, pois estamos tratando do devir da profissão que escolhemos como nossa. E ao mesmo tempo, da garantia da qualidade dos serviços prestados à população usuária dos serviços sociais.

Assim, apropriando-nos das reflexões de Florestan Fernandes, reafirmamos nosso compromisso com a classe trabalhadora, pois, ou nos identificamos com o destino do nosso povo, com ele sofrendo a mesma luta, ou nos dissociamos do povo, e nesse caso seremos aliados daqueles que exploram o povo.

\section{Conselho Federal de Serviço Social (CFESS) \\ Gestão Tempo de Luta e Resistência (2011-2014)}

